\title{
DIGITAL RECTAL EXAMINATION (DRE) DOES NOT INFLUENCE TOTAL SERUM LEVELS OF PROSTATE SPECIFIC ANTIGEN (TPSA), IN INDIVIDUALS WITHOUT PROSTATE PATHOLOGY
}

\author{
MARIA DE F. FIGUEIRÊDO, GALENO T. LOPES, TALAPALA G. NAIDU \\ Department of Pathology and Legal Medicine, Medicine School, Federal University of Ceará, Fortaleza, \\ Ceará, Brazil
}

\begin{abstract}
Objective: To evaluate if the digital rectal examination (DRE) performed before determination of total serum prostate specific antigen (tPSA) influences the levels of this protein.

Materials and Methods: Forty-eight men without a diagnosis of prostate pathology were assessed for tPSA levels, before and 30 minutes after DRE examination. Values of tPSA in the individuals' serum were measured by the electrochemoluminescence (ECLIA), in Roche's Elecys 1010 analyzer.

Results: DRE examination induced a modest elevation in tPSA values in 34 of the 48 men, with a variation in mean elevation from $2.19 \%$ in the age range $\geq 70$ years to $11.96 \%$ in the age range of 60-69 years. Additionally, moderate decreases in values were detected in 11 individuals and 3 did not present any alteration following the procedure. Differences in mean values of tPSA, pre- and postDRE were not statistically significant, neither in the total sample of individuals or in the age range groups.

Conclusion: DRE examination does not significantly influence the tPSA values in individuals under study.
\end{abstract}

Key words: prostate; prostate-specific antigen; diagnosis

Int Braz J Urol. 2003; 29: 423-7

\section{INTRODUCTION}

In many institutions the diagnosis of prostate pathologies, such as benign prostatic hyperplasia $(\mathrm{BPH})$ and prostate cancer (PCa), is made through clinical and laboratory procedures: digital rectal examination (DRE), assessment of serum total PSA (tPSA), ultrasonography and histopathologic examination in biopsies of the gland, usually in that order. The evidence of an altered structure of the gland through DRE and/or tPSA value above $4 \mathrm{ng} / \mathrm{mL}$, generally leads to the performance of a prostate biopsy for definitive diagnosis.
In a study with 199 men, Yuan et al. (1) observed that the DRE resulted in a transitory and nonsignificant elevation of tPSA in only $6 \%$ of men, while the performance of transrectal biopsy raised serum tPSA level in $92 \%$ of the cases. Significant alterations in serum parameter were detected by Crawford et al. (2) in some men with pre-DRE tPSA values below $4.0 \mathrm{ng} / \mathrm{mL}$. Chybowski et al. (3) assessed the effects of DRE in 71 patients with prostate pathologies and 72 controls and found that some individuals with initial PSA values up to $4.0 \mathrm{ng} / \mathrm{mL}$ presented a statistically significant elevation of serum PSA, but they regarded such alteration as having no clinical signifi- 
cance. In a more recent study, Lechevallier et al. reported that DRE induced a significant increment of total PSA in the peripheral bloodstream, mainly due to the elevation of free PSA. Conjugated PSA seemed to be less sensitive to the procedure (4).

Though DRE and tPSA examinations do not individually have a diagnostic value for prostate pathology, the association of both parameters was recommended as the most effective way for "screening" the risk population $(5,6)$.

Routine application of DRE before blood collection for dosing tPSA is performed in many centers that are specialized in prostate diseases. The availability of relatively few studies in literature about the effects of DRE on serum PSA and the lack of findings in literature about such assessments in our environment, led to the present study about the potential effects of digital rectal examination on serum total PSA levels (tPSA).

\section{MATERIALS AND METHODS}

During the period from June to September 2001, 48 men aged over 39 years were selected for this study. All men were asymptomatic concerning the prostate, and none of them had a history of systemic inflammatory disease. Men were grouped by the following age ranges: a) 39 - 49 years $(n=18)$; b) 50 - $59(n=18)$; c) $60-69(n=8)$; d $) \geq 70(n=3)$.

\section{Determination of tPSA}

Patients had their venous blood collected in sterile Vacutainer tubes without anticoagulant and centrifuged for serum separation. Quantitative dosing of tPSA was performed by the electrochemoluminescence immunoassay technique (ECLIA), using Roche's Elecsys 1010 analyzer. The first dosing was performed before DRE, and the second one within a 30-minute interval of this examination. Values were estimated in $\mathrm{ng} / \mathrm{mL}$ and expressed in means \pm standard deviation and medians. Results were analyzed for potential differences between median values, before and after DRE examination in the whole group of 48 individuals, as well as in each of the age ranges under study.

Differences between median values before and after DRE examination were assessed by
McNemar's test for comparing the medians of paired samples (7), as well as the difference in pre- and postDRE values in each age range to the significance grade of $p \leq 0.05$.

\section{RESULTS}

The DRE examination did not find detectable abnormalities in none of the 48 individuals, including the 3 men aged $\geq 70$ years, 2 of whom presented tPSA values above the values regarded as normal of $4.00 \mathrm{ng} / \mathrm{mL}$.

Before the DRE examination the individuals revealed a tPSA value of $1.37 \pm 2.01 \mathrm{ng} / \mathrm{mL}$ with the median values established in $0.99 \mathrm{ng} / \mathrm{mL}$ (Table-1). Two individuals from the investigational group, both above 70 years old, had values above $4.00 \mathrm{ng} / \mathrm{mL}$, one with 4.36 and other with $14.00 \mathrm{ng} / \mathrm{mL}$, which contributed to the high value of standard deviation around the mean evidenced in this group. Following the post-DRE 30-minute interval, the group presented values for mean \pm standard deviation and median, respectively, of $1.47 \pm 1.81$ and $1.13 \mathrm{ng} / \mathrm{mL}$. The difference between median values of tPSA, before and after the examination, was minimal and non significant ( $p>0.05)$. In a new tPSA assay after DRE examination the same 2 individual that had revealed values above $4 \mathrm{ng} / \mathrm{mL}$, maintained values above this threshold (4.35 and $13.00 \mathrm{ng} / \mathrm{mL}$, respectively) contributing, once more to elevating the standard deviation around the mean (Table-1).

The group's mean values of tPSA were approximately $37 \%$ higher than the medians, both before and after DRE, proving that the median reflected the value distribution of the group in a more reliable way, without being excessively influenced by individual values that are largely different from the average. The expressive majority of individuals shows a trend of having presented some elevation in TPSA values following DRE (34 dos 48), and 3 maintained themselves at the same threshold, while 11 demonstrated a slight decrease in the levels of this serum protein, including the 2 individuals with values above $4.00 \mathrm{ng} / \mathrm{mL}$.

The values of mean \pm SD and median of the age range groups are presented in Table-2. Data re- 
veal that mean values of tPSA progressively increase from the lowest age range to the range $\geq 70$ years. The group $\geq 70$ years evidenced the highest mean value of all four age ranges, influenced by 2 individuals' high values.

Median values of the age ranges also recorded a progressive elevation with increasing age, except for the group from 50 - 59 years whose median value, below the other ranges, was maintained after the DRE examination. The difference in pre- and post-DRE median values was not statistically significant in any age group $(\mathrm{p}>0.05)$.

The percentage of variation in the tPSA mean levels, before and after DRE examination in the age groups are presented in Table-2. DRE procedure caused the lowest variation for levels higher than $2.19 \%$ in the group $\geq 70$ years, and the highest increase of $11.96 \%$ in individuals between 60-69 years. A progressive increase in the percentage of elevation in tPSA mean values was found in the first 3 age groups $(7.07 ; 11.18$ and 11.96 , for the $39-49,50-59$ e $60-69$ years ranges, respectively), with a drop to $2,19 \%$ being recorded then in the group $\geq 70$ years.

\section{DISCUSSION}

DRE and determination of serum PSA are regarded as highly valuable for "screening" male population in ages that are more susceptible to prostate pathologies (8-11). In comparative terms, the increase in serum PSA levels seem to better correlated to the evolution of prostate pathologies (12), but this protein can be high in other conditions unrelated to the prostate $(13,14)$, which renders difficult the use of this marker as an exclusive parameter for diagnosis of $\mathrm{PCa}$ and $\mathrm{BPH}$. Even though rectal examination allows a direct assessment of structural changes of the prostate and surrounding tissues, DRE examination is considered less sensitive than PSA determination, particularly for detecting diseases in an early stage of development. Such considerations have largely contributed for recommending the use of both procedures in combination for routinely "screening" the male population for detection of prostate pathologies $(5,6)$.
When DRE examination is performed before the dosing of serum PSA, the use of post-rectal palpation PSA values as reliable markers of true values for the individual could be compromised, in principle, if such examination induces significant changes in the serum protein. Such possibility was investigated in some studies, mainly in the USA (1-3) and in France (4), with observations suggesting that DRE induced, in a general way, minimal changes in serum levels of PSA, which did not significantly compromise the use of this parameter. However, doubts seem to persist on this respect (4).

For the present study, the urology team of the institution determined the 30-minute interval between DRE examination and the new dosing of tPSA. Previous works used intervals between DRE and the assessment of PSA, ranging from a few minutes and up to 90 minutes following digital rectal examination $(1,2)$, however without finding significant differences in values that could be attributed to the post-DRE measuring time. The interval employed in this work is the same one used in the study by Lechevalier et al. (4).

Present data reveal that DRE resulted, almost always, in increase in the tPSA value, of about 8 to 13\% (Tables-1 and 2). This observation is in accordance, in general terms, to reports by Stamey et al. (15) and by Brawer et al. (16), during the 80s, and in subsequent studies (1-4).

Since DRE is a non-traumatizing and minimally stressing technique to the individual, it seem

Table 1 - Pre-and post-digital rectal examination (DRE) values of total PSA (tPSA) in individuals without prostate pathology.

\begin{tabular}{lll}
\hline Parameter & \multicolumn{2}{c}{ tPSA $(\mathbf{n g} / \mathbf{m L})(\mathbf{n}=48)$} \\
& Pre-DRE & Post-DRE \\
\hline Median value & $0.99^{*}$ & $1.13^{*}$ \\
Mean \pm SD & $1.37 \pm 2.01$ & $1.47 \pm 1.81$ \\
\hline
\end{tabular}

* Difference between the values was not statistically significant $(p>0.05)$. tPSA values increased in 34 individual, decreased in 11 and remained unchanged in 3. 
Table 2 - Pre-and post-digital rectal examination (DRE) values of total PSA (tPSA) in individuals without prostate pathology, according to age range.

\begin{tabular}{lcccccc}
\hline $\begin{array}{l}\text { Age Range } \\
\text { (years) }\end{array}$ & N & \multicolumn{2}{c}{$\begin{array}{c}\text { Pre }- \text { DRE } \\
\text { tPSA }(\mathbf{n g} / \mathbf{m L})\end{array}$} & \multicolumn{2}{c}{$\begin{array}{c}\text { Post }- \text { DRE } \\
\text { tPSA }(\mathbf{n g} / \mathbf{m L})\end{array}$} & $\begin{array}{c}\text { Increase in mean } \\
\text { value following DRE (\%) }\end{array}$ \\
\hline $39-49$ & 18 & $1.35^{*}$ & $0.99 \pm 0.90$ & $1.34^{*}$ & $1.06 \pm 0.88$ & 7.07 \\
$50-59$ & 18 & $0.31^{*}$ & $1.02 \pm 0.57$ & $0.34^{*}$ & $1.14 \pm 0.64$ & 11.18 \\
$60-69$ & 09 & $2.02^{*}$ & $1.17 \pm 0.64$ & $2.12^{*}$ & $1.31 \pm 0.67$ & 11.96 \\
$\geq 70$ & 03 & $3.03^{*}$ & $5.02 \pm 6.03$ & $3.09^{*}$ & $5.13 \pm 5.35$ & 2.19 \\
\hline
\end{tabular}

* There was no statistically significant difference between pre- and post-DRE values in none of the age ranges under study.

reasonable to assume that he effects of DRE examination are not long lasting to the point of maintaining PSA alteration for a long time. The modest rise in mean and median values of tPSA following the performance of the DRE was not shown to be statistically significant, which is in accordance to other reports in the literature (1-16), however it does not corroborate the observations of studies that found a significant increase in serum PSA values following digital rectal examination $(2-4,15)$. The increase in postDRE PSA, of about 1.5 to 2.0 times above the initial values as reported by Stamey et al. (15), was not corroborated in none of the subsequent studies, including the present work.

In this study, in addition to moderate increases in the majority of individuals assessed, DRE has also caused a decrease in TPSA values in 11 of the 48 individuals, with other 3 that did not present any change in their levels. This finding seems to suggest that DRE does not contribute, in fact, for a significant change in mean or median profile of tPSA in this group of individuals (men with no diagnosed prostate pathology). In this aspect, this work, which was performed with a group of only 48 healthy individuals, directly and favorably parallels with the conclusion by Crawford et al. (2), that DRE did not result in significant changes in the PSA level.

Data from Table-2 reveal that the percentage of DRE-induced increase in mean tPSA values relates to the increasing age of the male population, in a crescent way, from the age range of 39 - 49 years to the range of $60-69$ years. Such data is in accordance, in a general way, to the well-known elevation of PSA with increasing age. Despite this effect of age over tPSA in older individuals, the differences found in values of age ranges were not significant.

Finally, we observed that the group of individuals aged $\geq 70$ years had a decrease in tPSA value following the DRE procedure. Considering that there were only 3 individuals in this age range, the observation becomes little relevant. Even if we disregard the tPSA values of the group $\geq 70$ years, it is evident that the digital rectal examination induced some alteration for higher tPSA values in approximately $72 \%$ of the individuals assessed. However, this modest elevation does not seem to be significant so to negatively influence the use of post-DRE tPSA values as reliable markers.

Maria de F. Figueiredo had a scholarship from $\mathrm{CNPq}$ - Brazil

\section{REFERENCES}

1. Yuan JJ, Coplen DE, Petros JA, Figenshau RS, Ratliff TL, Smith DS, et al.: Effects of rectal examination, prostatic massage, ultrasonography and needle biopsy on serum prostate-specific antigen levels. J Urol. 1992; 147 (Pt 2): 810-4.

2. Crawford ED, Schutz MJ, Clejan S, Grago J, Resnick MI, Chodak GW, et al.: The effect of digital rectal examination on prostate-specific antigen levels. JAMA. 1992; 267: 2227-8.

3. Chybowski FM, Berstralh EJ, Oesterling JE: The ef- 
fect of digital rectal examination on the serum prostate-specific antigen concentration: results of a randomized study. J Urol. 1992; 148: 83-6.

4. Lechevallier E, Eghazarian C, Ortega JC, Roux F, Coulange C: Effect of digital rectal examination on serum complexed and free prostate-specific antigen and percentage of free prostate-specific antigen. Urology. 1999; 54: 857-61.

5. Vieira JGH, Nishida SK, Pereira AB, Arraes RF, Verreschi TN: Serum levels of prostate-specific antigen in normal boys throught puberty. J Clin Endocrinol Metabol. 1994; 78: 1185-7.

6. Garzotto M, Hudson RG, Peters L, Hsieh YC, Barrera E, Mori M, et al.: Predictive modeling for the presence of prostate carcinoma using clinical, laboratory, and ultrasound parameters in patients with prostate specific antigen levels $<$ or $=10 \mathrm{ng} / \mathrm{mL}$. Cancer. 2003; 98: 1417-22.

7. Sachs L: Estatística Aplicada. Barcelona, Editorial Labor. 1978.

8. Galic J, Karner I, Cenan L, Tucak A, Hegedus I, Pasini $\mathrm{J}$, et al.: Comparison of digital rectal examination and prostate specific antigen in early detection of prostate cancer. Coll Antropol. 2003; 27 (Suppl 1): 61-6.

9. Miller DC, Hafez KS, Stewart A, Montie JE, Wei JT: Prostate carcinoma presentation, diagnosis, and staging: an update form the National Cancer Data Base. Cancer. 2003; 98: 1169-78.
10. Becciolini A, Porciani S, Lanini A: Marker determination for response monitoring: radiotherapy and disappearance curves. Int J Biol Markers. 1994; 9: 38-42.

11. Carter HB, Pearson JD, Metter EJ, Brant LJ, Chan DW, Andres R, et al.: Longitudinal evaluation of prostatespecific antigen levels in men with and without prostate cancer. JAMA. 1992; 267: 2215-20.

12. Roehrborn CG, Gregory A, McConnell JD, Sagalowsky AI, Wians FH Jr.: Comparison of three assays for total serum prostate-specific antigen and percentage of free prostate-specific antigen in predicting prostate histology. Urology. 1996; 48 (6A Suppl): 23-32.

13. Rhoden EL, Riedner CE, Maffesson R, Gobbi D, Teloken C, Souto CAV: Free to total prostate-specific antigen ratio for the diagnosis of prostate cancer. Int Braz J Urol. 2001; 27: 454-60.

14. Maciel LMZ, Martins ACP, Falconi RA, Cologna AJ, Suaid HJA: Comparative study of assays for prostatespecific antigen (PSA) determination. Int Braz J Urol. 2001; 27: 542-8.

15. Stamey TA, Yang N, Hay AR: Prostate-specific antigen as a serum marker for adenocarcinoma of the prostate. N Engl J Med. 1987; 317: 909-16.

16. Brawer MK, Schifman RB, Ahmann FR, Ahmann ME, Coulis KM: The effect of digital rectal examination on serum levels of prostate-specific antigen. Arch Pathol Lab Med. 1988; 112: 1110-2.

Received: January 29, 2003 Accepted after revision: June 11, 2003

\footnotetext{
Correspondence address:

Dr. Talapala G. Naidu

Rua Vilebaldo Aguiar, 95 / 903

Fortaleza, CE, 60190-780, Brazil

E-mail: talapala_gn@yahoo.co.uk
} 